\title{
Shrinking core? Exploring the differential agenda setting power of traditional and personalized news media
}

\author{
Judith Moeller, Damian Trilling, Natali Helberger, Kristina Irion and Claes De Vreese
}

\author{
Judith Moeller and Damian \\ Trilling are both based at the \\ ASCoR Amsterdam School of \\ Communication Research, \\ Department of Communication, \\ University of Amsterdam, \\ Amsterdam, The Netherlands. \\ Natali Helberger is Professor \\ and Kristina Irion is Senior \\ Researcher, both at the IViR \\ Institute for Information Law, \\ University of Amsterdam, \\ Amsterdam, The Netherlands. \\ Claes De Vreese is based at \\ the Amsterdam School of \\ Communication Research \\ ASCoR, University of \\ Amsterdam, Amsterdam, The \\ Netherlands.
}

\begin{abstract}
Purpose - This paper aims to shed light on the impact of personalized news media on the shared issue agenda that provides democracies with a set of topics that structure the public debate. The advent of personalized news media that use smart algorithms to tailor the news offer to the user challenges the established way of setting the agenda of such a common core of issues.

Design/methodology/approach - This paper tests the effects of personalized news use on perceived importance of these issues in the common core. In particular, the authors study whether personalized news use leads to a concentration at the top of the issue agenda or to a more diverse issue agenda with a long tail of topics.

Findings - Based on a cross-sectional survey of a representative population sample $(\mathrm{n}=1,556)$, we find that personalized news use does not lead to a small common core in which few topics are discussed extensively, yet there is a relationship between personalized news use and a preference for less discussed topics. This is a result of a specific user profile of personalized news users: younger, more educated news users are more interested in topics at the fringes of the common core and also make more use of personalized news offers.

Research limitations/implications - The results are discussed in the light of media diversity and recent advances in public sphere research.

Originality/value - This paper contributes to the ongoing debate about algorithmic news dissemination. While, currently, much attention is reserved for the role of platforms as information gatekeepers in relationship to the news media, maybe their ability to enable or hinder the audience in discovering and distributing news content is part of what really characterizes their influence on the market place of ideas.
\end{abstract}

Keywords Worldwide web, Communication technologies, Statistical analysis, Television news

Paper type Research paper

Kristina Irion, Claes de Vreese.

Published by Emerald Group

Publishing Limited. This article is published under the

Creative Commons Attribution (CC BY 3.0) licence. Anyone may reproduce, distribute, translate and create derivative works of this article (for both commercial \& non-commercial purposes), subject to full attribution to the original publication and authors. The full terms of this licence may be seen at

http://creativecommons.org/ licences/by/3.0/legalcode. Received 16 May 2016 Revised 8 July 2016 Accepted 11 July 2016

This work was supported by the European Research Council under Grant 638514 (PersoNews).

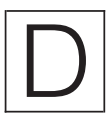
etermining a shared issue agenda within the public sphere is one of the central functions of news media in democratic societies (Chaffee and Metzger, 2001). Since the advent of the mass media in the twentieth century, it has been the role of newsrooms of newspapers and TV news to select relevant events and topics and decide upon their relative importance, by determining what is placed on the front page and what is published in the midsection of the newspapers (White, 1950). Hence, when these news agendas are roughly similar, news media are able to put core issues on a common agenda and discuss them from different viewpoints.

A diverse discourse about a limited set of relevant topics is genuinely considered to be a critical condition for a public sphere and for cohesion in modern democracies. However, technological advances like customizable online news media, smart algorithms that create personalized online news sites or news sharing on social media have substantially changed the news landscape. These new modes of news exposure challenge the classic top-down agenda-setting model (Castells, 2007), and as a result, two seemingly contrasting, but not mutually exclusive effects might occur. First, there could be an increased concentration of attention toward to a small set of news events at the top, at the 
expense of attention toward the bulk of ordinary news stories. Hindman, for instance, argues that news use is increasingly adapting to a "winner takes all" (2009, p. 91) pattern. Second, news events in the long tail (i.e. events of which each part only gets a negligible share of attention; Anderson, 2004) could - taken together - matter to more and more news users.

In this paper, we explore this relationship between personalized news use and agenda diversity relying on survey data collected among a representative sample of the Dutch population. We further investigate whether and how this relationship can be explained by looking at the background and the attitudes of personalized news users.

This paper adds to the ongoing debate about the fragmentation of the public sphere (Sunstein, 2009; Pariser, 2011) and curated news flows (Thorson and Wells, 2015) by providing empirical evidence of the effects of personalized news use on the issue agenda. As this study is carried out within the context of a European multi-party system, we furthermore expand the scope of the mostly US-centric debate, which is heavily influenced by the bipolarity of the American party system. By comparing personalized news use to alternative modes of news use, we account for the diversity users experience in their media diet. Therefore, we can show the function of personalized news in the concert of the overall news use.

The findings in this paper add furthermore to the debate in media law and policy. Also, in media law and policy, the particular role of the media as a public forum and catalyst of the public debate through the creation of a "democratic and participatory public sphere" has been acknowledged (Council of Europe, 2007), and has informed law and policy making. A relevant question in this context is how the changes in the media landscape and in users' media consumption behavior affect the realization of media diversity on the one hand, and policies that are directed at facilitating and fostering the role of the media as a "general interest intermediary" (Sunstein, 2009) on the other hand[1]. Insofar, the article contributes, in particular, to the further development of the aspect of exposure diversity, a so far underdeveloped aspect of media diversity policies. As Napoli (2011) observed, diversity of exposure "resided very much at the margins" of policy debate and making "despite the centrality of the concept" (ibid.) to the rational of interventions in the media sector. While this statement relates to the USA, it is in every respect true for European media policy (Karppinen, 2010; Valcke, 2011b). Only recently there is a new interest in media law scholarship in studying and understanding exposure diversity (Breeman et al., 2011; Helberger, 2012). In addition, the findings in this paper can inform the ongoing debates about the European Commission's initiatives in the area of platforms (European Commission, 2013, , 2015; High Level Expert Group on Media Freedom and Pluralism, 2013), and more generally, European and national media diversity policies.

\section{The value of a common core}

The common core defines the agenda of the public sphere, namely, issues that are being discussed by the majority of the population (McCombs and Shaw, 1972). A shared common core of issues is generally considered to be a crucial condition in modern democracies because it enables some of the core principles of democratic societies:

\section{Free market place of ideas}

The market place of ideas metaphor essentially frames the function of the public sphere as a discovery procedures in which information, ideas and opinions compete in what Schauer (1982) has once described as an "advisory process" with the ultimate goal that the truth or the most convincing ideas prevails. While there should not be any limitations on which issues enter the market place of ideas, the notion of a market place only works if all relevant players are able to offer their idea on a specific issue - the common core - so citizens can 
choose between the various alternatives. This requires a shared discourse about a limited set of topics.

\section{Public forum}

Yet, the agenda of the public sphere in a democracy are not asymmetrically set by the elites. Ideally, citizens engage in the public sphere and develop a common agenda that feeds into the political process (Curran, 1991). Following the work of Habermas (1987/1981), ideally, this exchange of ideas would lead to better ideas prevailing. Politicians, in turn, can react to issues and events that are important to the citizenry, and citizens themselves can take action by forming social movements that aim to change public policies. From this perspective, one could argue that the common core is also the place where Russeau's volunte general can become apparent.

\section{Accountability and transparency}

In representative democracies, citizens legitimize representatives through elections to take decisions on common policies. To take an informed electoral decision, citizens rely on information from newspapers (which, therefore, can be seen as facilitators of a public sphere) to evaluate the accountability of the elites in power, taking into account the performance or failure of the candidates as well as their issue stances (Schumpeter, 1942). Did the representatives hold true on their electoral promises? Did they truly act in the benefit of the groups of their voters? To reliably evaluate these issues, citizens need access to current elite debates in which the positions of the various players become transparent. To generate electoral support, representatives also need to be able to present themselves and, more importantly, their political program and choices to the electorate. In other words, a mass mediated description of the elite discourse is an important pre-condition of transparency and accountability in a democratic society. However, it should be noted that this traditional role of the mass media has been challenged in recent years. For example, changes in the ownership structure of news media through privatization and deregulation have brought about serious threats for the editorial independence of news rooms (Fenton, 2015). As a result, processes of collective decisions making have become increasingly difficult. Gilbert (2014) even signals a "democratic crisis".

\section{Informed citizens}

Closely related to the market place of ideas and the aforementioned issues of accountability and transparency is the conceptualization of the user as an informed citizen and decision maker on the very same market place. To be able to weight the different ideas and opinions and judge them upon their merits, citizens need to be reasonably well informed, interested in a diversity of issues and practiced in critical thinking, or in the words of Meiklejohn (1948), "The voters, therefore, must be made as wise as possible. The welfare of the community requires that those who decide issues shall understand them [. . . This in turn requires that so far as time allows, all facts and interests relevant to the problem shall be fully and fairly presented [. . . B Both facts and interests must be given in such a way that all the alternative lines of action can be wisely measured in relation to one another". This conception of the citizen as informed actor on the market place of ideas still underlies today's thinking about the role of the media in a democratic society and the role of media diversity policies in particular. Note that this is also the conception of the user as "information all-rounder" rather than specialist, which can be at odds with the realities in today's media markets (see below).

\section{Cohesion and tolerance}

Furthermore, a common core of issues is important for societal cohesion. It provides citizens with something in common and, therefore, allows for communication among the citizenry. In the complete absence of a common core of issues, it would be virtually 
impossible to have a discussion. On a larger scale, a common core of issues a society cares about provides a shared identity that defines the citizenry of a democracy. A related aspect is the aspect of cultural integration: by exposing citizens to a diversity of not only shared opinions but also differences in the society, the media, and diverse exposure, can also play an important role in fostering tolerance and open-mindedness to also those that are "different" from users' own beliefs and convictions. Especially, in today's climate of cultural confrontations and social disagreement, the common core can also have an important integrating, tolerance-enhancing role.

It is important to note that the function of the public sphere within a democracy depends on the conceptualization of democracy (Ferree et al., 2002). For example, a representative liberal democratic model relies heavily on accountability that is created through making elite discourses and decisions transparent to voters, whereas from a deliberative perspective, a discursive public forum is far more essential. Another important aspect, as mentioned above, is the conceptualization of the user as either information all-rounder, who aims at achieving a fairly balanced and complete idea of the issues that play in a society, as self-interested maximizer of her own pleasure (typically the conception of the citizen as information consumer) or the citizen as amateur-expert (Helberger, 2008a).

\section{The flip side: constraints imposed by a common core of issues}

On the other hand, the effect of a common core of issues or a public agenda that features only a small set of issues on democratic principles in not straightforward positive. On the contrary, the agenda-setting power of the elite has been challenged and contested for decades, in particular, because of the small set of issues that emerges from the process, and also because of the alleged lack of responsiveness of the traditional news media to the diversified interests of a heterogeneous audience (Ytreberg, 2002). In recent years, additional challenges in the form of a steadily growing information offer that competes for the attention of users have arisen.

In a situation that the discourse is focused on a very limited set of topics, most events happening and issues that arise are not being discussed publically and, therefore, gain little to no attention. Hence, for these issues, there is neither accountability generated, nor is there a visible market place of ideas or a public forum that weighs alternative solutions against each other. This has two negative consequences for democratic societies: first, setting the agenda becomes an extremely powerful tool to control public discourse. This power is mainly in the hands of the elites, which leads to asymmetric distribution of power and access to public discourse. More related to today's situation: powerful platforms with far-reaching possibilities to control the exposure of users to content, e.g. as a result of the knowledge that these platforms have about users, the ability to influence their choices and also the control over recommendation systems and access to an audience. Second, topics of high relevance for the population might be overlooked because of the scrutiny of the short agenda. Accordingly, one important task of diversity policies is it to make sure that the audience is exposed to a certain (unspecified) mix of diverse information within a medium (i.e. the concept of internal diversity of, for example, the programs and website of the public service media) and a diverse selection of competing outlets (external diversity). Insofar, there is also a potential tension between the ideas of and behind a shared and common core and the requirements of a diverse information offer as precondition for informed and open-minded citizenry. We can conclude that democratic societies cannot do without a shared common core, yet the common core should only be the start and not the end of the shared agenda.

\section{Media influence on the common core: mainstreaming or cohesion?}

Mass media have served as the stage on which the public sphere is perceived for the better part of the twentieth century. Before the media landscape was transformed into 
what Prior (2007) calls the post-broadcasts democracy, newspapers, TV shows and news magazines defined the common core of issues that formed the agenda of the public discourse (McCombs and Shaw, 1972). In essence, newsrooms and editorial boards selected out of the infinite number of events taking place in a day those events that were going to be the subject of public discussion the next day, based on news value of the event and their professional code. To this day, journalists regard it as an important tasks to keep the gates of the news public debate. Critics, most notably Chomsky (1997), refer to this process as mainstreaming because it essentially removes the long tail on the public discourse, focusing everybody's attention on a few select issues.

New modes of news consumption have revolutionized this process (Zuckerman, 2014). Citizens can now take a more powerful position on the sending end of the communication flow. By sharing and forwarding information to their peers, social media users have become to some extent also each other's gatekeepers. They curate each other's communication flow, which leads to a situation in which different gatekeepers exist next to each other (Thorson and Wells, 2015). This is often done by sharing news stories through social media that were originally published on traditional news website. In the case of The Netherlands, the commercial database similarweb.com suggests that Dutch newspaper websites get about 15 per cent of their visits directly from links on social media. Such third-party estimates have to be taken with a grain of salt, but nevertheless, they indicate that a substantive number of people receive news via social media. Figures occasionally published by the Dutch newspaper site volkskrant.nl (www.volkskrant.nl/dossier-redactieblog/) even suggest higher percentages. A recent report by PEW finds that six of ten Americans regularly get news through social media[2].

But the role of citizens on the receiving end has also changed due to the increase of available information fueled by technical developments like digitalization and the advent of the World Wide Web. The normative ideal of the informed citizens that felt responsible to be thoroughly informed about all issues at stake has been complemented by the norm of the monitorial citizen (Schudson, 1998), implying that rather than processing all available information on current events, citizens now also can scan them efficiently to identify issues they can and should engage in. As a consequence, the citizen as information all-rounder is making place to the citizen as amateur-expert. Keane (2009) relates this notion directly to the over-saturation of the available information in the fragmented media landscape. Citizens are forced to strategically select a small set of issues they feel they are best fit to be efficacious in and become engaged. These issues are, in many instances, not at the top of the shared agenda, but issues on the long tail, to which individuals can contribute because of their expertise as professionals, residents in a specific area or personal interest for a specific issue ranging from protecting the rain forest to traffic regulation. A recent study that was part of the Reuters Digital news report[3] finds that users indeed value services that tailor news to their interest over the selection of news by editors.

However, the very same mechanisms that increase diversity on the issue agenda could also lead to a concentration at the top. Social media are a fast medium. When important news events are happening they are rapidly disseminated through social media. Through what can be considered a snowball effect the same topics increase visibility on social media platforms, which in turn leads to even more sharing and forwarding.

Studies on news dissemination or news diffusion have addressed such topics from various angles. For example, it can be shown how the connectivity of the first Facebook users sharing some content predicts the eventual structure and size of the cascade in which the information spreads (Cheng et al., 2014) and that only very few hops in such a cascade are needed to reach a substantial audience on Twitter (Kwak et al., 2010). Because of the importance of the structure of such information cascades for the 
question whether a given news item reaches a given user, the notion of opinion leadership has become relevant again. It seems that those who see themselves as opinion leaders share different information than others (Bobkowski, 2015), and it also can be shown that partisanship influences news sharing on social media (Weeks and Holbert, 2013).

Clearly, the assumption that there is a clearly defined actor that can be identified as the source of an agenda-setting process does not hold any more for news consumption in this new ecosystem. We do not necessarily want to go as far as Russell Neuman et al. (2014), who argue that the question "who sets the media agenda?" has become "ill structured", but at the very least, it seems that we have to understand how agendas of the users of such new news sources actually look like.

Some first evidence suggests that there might indeed be differences compared to traditional media: For example, Singer et al. (2014) investigated user attention on the social media news platform reddit over time. They found that while the topics that are being posted become more and more diverse over time, user attention and use is concentrated on only a small set of subtopics. Hindman (2008) calls this the "winner takes all principle" of the Internet, which does not only reaffirm the agenda-constraining function of the traditional news media, it even surpasses it. In practice, this means that the personalization of the news agenda leads in many instances to a concentration of issue agenda, which is counter-intuitive only at the first glance.

\section{Exploring the effect of personalized media on issue diversity}

Combining both assumptions, the development could be understood as almost paradoxical: more different topics are shared (hence, a large long tail is formed), but of this larger range, only very few are shared with almost everyone (winner-takes-all pattern at the top). We hypothesize:

H1a. The more personalized the news menu of an individual, the higher the chance that what he/she perceives as the most important topic is the topic that is perceived by most people as the absolutely most important one ("winner takes all" effect).

H1b. The more personalized the news menu of an individual, the higher the chance that what he/she perceives as the most important topic is not even among the top 10 topics ("long tail" effect).

Thus, the more personalized the news menu of an individual, the less likely we expect it to be among the medium category if we rank all answers by popularity.

The results of our inquiry will not only advance our knowledge about how people engage with diverse news content. They are also very relevant from a public policy point of view as they may require us to rethink some of the basic assumptions today's media pluralism policies are based on. If confirmed, our results call into question the idea that the media are, through offering a diverse media diet, primarily responsible for diverse exposure and are in so doing so contributing to the formation of a well-informed and active public sphere with a stable core of common topics and interests. Instead, the actual diversity of media contents consumed is to a considerable degree also user-driven, and the actual diversity for more user-driven forms of (diverse) agenda setting differs from the diversity that the media, as the traditional agenda setters produce.

\section{Method}

We rely on cross-sectional survey data collected among a representative sample of Dutch adults $(n=1,556)$. Data were collected through Computer Assisted Web Interviewing in the period from October 5, 2015, to November 14, 2015. The survey was administered by the Dutch polling company CentERdata and drawn from the Dutch academic household panel LISS panel. 


\section{Measures}

Top topic and long tail topic. The first question of the survey asked respondents to name the most important news event of the last week in an open format. We subsequently coded the open answers and organized them into categories of topics. Then, for each Day d, we calculated the frequencies with which each news event or topic was mentioned within a moving window of three days (with the exceptions of Day 1 and Day 2, for which we took the values of the day itself), thus on $d, d-1$ and $d-2$. These frequencies where transformed into rank scores. Thus, each topic can have a potentially different rank on each day.

To each respondent $r$, we then assigned the value RS_r(topic_r,day_r $)$, depending on the day on which he/she answered the questionnaire and the topic he/she mentioned. This variable was further recoded into two variables. Top (mean $=0.69, S D=0.45)$ represents topics that ranked first on the day of the interview and long tail ( mean $=0.17$, $\mathrm{SD}=0.38$ ) represents topics that were the fifth most important topic on the respective day or lower. These two variables are the main dependent variables in this study.

Personalized news use. Personalized news use was measured as the self-estimated percentage of online news that people receive via Facebook (mean $=19.04, \mathrm{SD}=25.19$ ). We use Facebook here as a proxy for personalized news use because, compared to other possible platforms like Twitter or news aggregator sites, it was by far most widely used for this purpose and because it has the highest degree of personalization. For example, at the time of our study, Twitter showed all items shared by one's connections in one's timeline, while Facebook's algorithm made a personalized selection.

Other modes of news use. Other modes of news use were measured using the standard item: How many days in a normal week do you use [. . .] to access news" Newspapers $($ Mean $=3.33, \mathrm{SD}=2,84)$; News on a website $($ Mean $=3.03, \mathrm{SD}=2.76)$, App on a mobile device $($ Mean $=1.96, \mathrm{SD}=2.72)$, TV news $($ Mean $=4.89, \mathrm{SD}=2.42)$, and Radio $($ Mean $=3.47, \mathrm{SD}=2.67)$.

Attitudes. We also measured normative expectations toward news media to provide a common core of issues as well as diversity. In particular, we asked people for their perceived importance of the common core using the item "There are news and current affairs that everyone should be aware of" (mean $=5.52, \mathrm{SD}=1.50$ ) and perceived importance of diversity using the item "If a news site could take my preferences into account I would wish to receive more diverse news" ( mean $=3.66, \mathrm{SD}=1.70)$.

\section{Results}

The first step in our analysis is to investigate the relationship between modes of access to news and the diversity of the agenda. Specifically, we compare the direction and strength of the correlation between the different modes and the likelihood that the perceived most important topic is at the top or the long tail of the shared issue agenda.

Table I provides an overview of the coefficients. The results indicate that there is a significant correlation of use of personalized news use and issue diversity, but only partly in line with $\mathrm{H} 1 \mathrm{a}$ and $\mathrm{H} 1 \mathrm{~b}$. Users of personalized news indeed are more likely to report an issue that is in the long tail of the shared agenda. They are, contrary to our expectation, less likely to report a topic at the top of the agenda. This means that we find no evidence of the winner takes all principle with regard to personalized news use. However, this effect is clearly discernable for classic mass news media newspaper and TV. Here, we find a highly significant correlation, which means that users of traditional mass news media are more likely to name the topic at the top of the shared issue agenda as the most important topic.

Yet, correlation does not necessarily imply causality. It only means that the two phenomena exposure to personalized news and agenda diversity occur among the same set of news users. But it might very well be that at the root of this relationship is not the mode of news 
Table I Spearman's rho coefficients for non-parametric correlations of key study

\begin{tabular}{lcc} 
Variables & Top & Long tail \\
\hline Personalized media & $-0.100^{* *}$ & $0.072^{*}$ \\
Newspaper & $0.059^{*}$ & -0.051 \\
Online news website & -0.037 & 0.036 \\
News on mobile devices & -0.042 & 0.041 \\
TV news & $0.145^{\star *}$ & $-0.128^{* *}$ \\
Radio news & 0.023 & -0.014 \\
Notes: $n$ 's range from 750 to 1,250 due to missing values; ${ }^{*} p<0.05 ;{ }^{* *} p<0.01$ &
\end{tabular}

use, but characteristics of the news users themselves. In the following, we investigate two of these potential factors - the social economic background of a person as well as their attitudes toward diversity in news media using logarithmic regression in which first social demographic background variables and then attitudes toward agenda diversity are entered as control variables.

Table II yields the results of the effect of personalized news use on issue diversity when socio-demographic background factors are controlled. We find that the relationship is no longer significant. Specifically, this means that the variables age and education predict the variance that was formerly explained by personalized news use. In other words, younger and higher educated news users are more likely to use personalized news use and they are also more likely to have a more diverse agenda. However, it should be noted that the full model only explains a small share of the variance in the dependent variable top and long tail. That means that there are other, unobserved underlying mechanisms at play that are important in determining whether a person names an issue at the top or the bottom of the shared issue agenda as most important to herself.

Turning to attitudes toward diversity as explanation of the relationship of personalized news use (Table III) and agenda diversity our findings indicate that attitudes are less powerful factors in this context. Perceived importance of the common core did not significantly affect a concentration of topics at top, meaning that news users who think it is important that there is a common core are not more likely to name the most important issue as their personally most important issue. The negative relationship of personalized news use and concentration at the top remains significant, which means that the users with the same attitude toward diversity significantly differ in their agenda diversity if they use personalized news. When we look at the long tail of the news agenda attitudes are relevant according to our results. Interestingly, we find that perceived importance of a diverse agenda is negatively associated with likelihood to name a long tail issue as the most important one. Again, it should be noted that the overall model fit is low.

Table II Summary of logistic regression analysis for variables predicting personal issue at the top $(n=750)$ and at the long tail of the public agenda ( $n=750)$, controlling for background variables[4]

\begin{tabular}{|c|c|c|c|c|c|c|}
\hline Predictor & B & $\begin{array}{l}\text { Top } \\
\text { SE(B) }\end{array}$ & $e^{B}$ & B & $\begin{array}{l}\text { Long tail } \\
\text { SE(B) }\end{array}$ & $e^{B}$ \\
\hline Personalized news media use & -0.002 & 0.004 & 0.998 & 0.002 & 0.004 & 1.002 \\
\hline Age & $0.021^{\star *}$ & 0.005 & 1.021 & $-0.021^{*}$ & 0.006 & 0.979 \\
\hline Gender & -0.018 & 0.169 & 0.982 & -0.119 & 0.197 & 0.888 \\
\hline Education & $-0.242^{* *}$ & 0.063 & 0.785 & 0.138 & 0.073 & 1.148 \\
\hline Constant & -0.869 & 0.535 & & -0.898 & 0.618 & \\
\hline - 2 Log likelihood & & 886.13 & & & 703.169 & \\
\hline Nagelkerke pseudo $R^{2}$ & & 0.09 & & & 0.05 & \\
\hline df & & 5 & & & 5 & \\
\hline
\end{tabular}


Table III Summary of logistic regression analysis for variables predicting personal issue at the top $(n=750)$ and at the long tail of the public agenda $(n=750)$, controlling for attitudes towards diversity

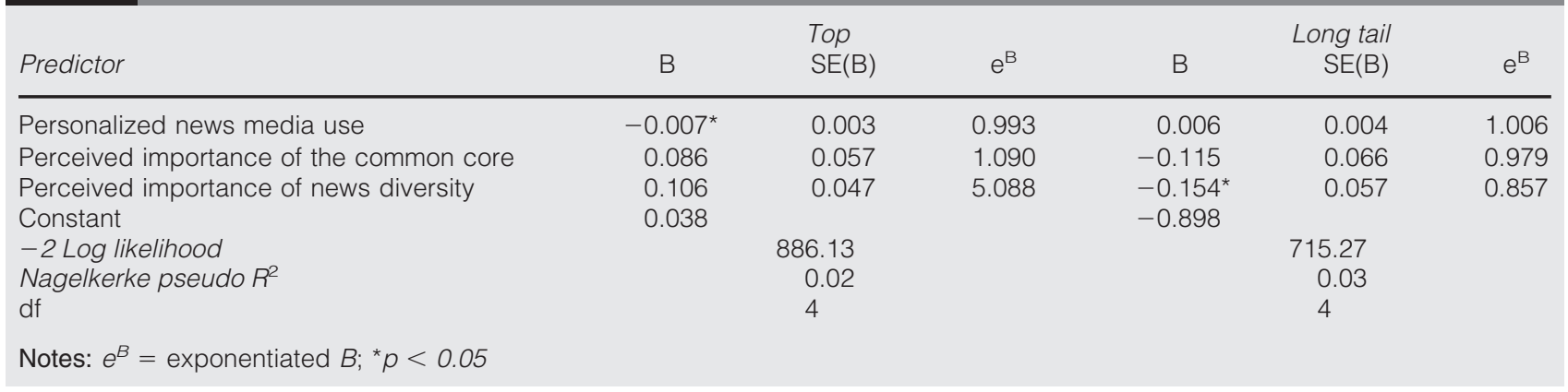

\section{Implications and discussion}

The results of our study suggest that due to personalized news use current events that are at the long tail of the public interest and attention gain traction at the expense of news events that were formerly relevant to many, but not all of the citizenry. However, this is not a consequence of the mode of news use itself, but marks a shift in the way younger, higher educated citizens use the news. They make use of access to news stories through social media, and they also focus on topics that might not have ended up on the cover of a traditional newspaper. According to our results, this finding is independent of the attitudes of news users toward agenda diversity. In fact, we found that users who value issue diversity are even less likely to deviate from the generally most important topic with regard to what was the most important news event in the past week.

\section{News curation and diverse exposure}

Our findings shed some light on the role of the user as active actors in self-organizing their own information agenda, and potentially also that of their friends on social media. While the traditional media have and will continue to have a role as agenda setter, users choose what kinds and range of contents they actually consume. One of the realities of the digital environment is that users have much more choices than in the old days of one public service broadcaster and a couple of newspapers. What is more, users choose not only between different news outlets, instead news consumption is far more disaggregated. Users can search, find and be exposed to single articles - through social networks, search or news aggregators such as Blendle. Accordingly, the role of users as co-agenda setters is more relevant. Hence, it is even more important to understand how users choose news content, what motivates their choices and to what extent are their choices conditioned by personal characteristics such as education or age.

The shift away from the common core does not necessarily have to be problematic for the public sphere. On the contrary, more attention for smaller issues might indicate a shift in perception of monitorial citizenship roles and can lead to more and different kind of diversity. This could be a concept of diversity that is less geared toward providing the citizen with all the information that she needs to carefully form her opinion on particular issues (in the sense of the classical "market place of ideas" conception of media diversity). Instead, it would give room to the discovery of ideas and opinions, standpoints and minorities that might have received less attention under the auspices of the news media as agenda setter. The role of the citizen is then more that of an expert who uses the media to inform herself specifically over particular topics on which she can then contribute an opinion. Maybe even that of an investigative amateur-curator who contributes issues and topics to the public debate that so far have remained invisible under the radar screen of the traditional mass media. Under such an alternative, maybe more "radical" (Karppinen, 2012) conceptualization of media diversity, the greater exposure for marginalized or less popular 
views and ideas could be actually seen as an opportunity, or the "missing link" to a truly informed citizenry. Media diversity as a concept is notoriously difficult to define, and even more so if it must guide the assessment of shifts in structure of diverse content that users ultimately consume. Maybe, it is time to acknowledge that next to the commonly accepted categories of diversity of supply, source diversity and diversity of exposure (Napoli, 2011) there is also something like "social diversity", i.e. the diversity that is the result from the way how users actively engage with, and share information, with the effect of also influencing the type of diversity that friends and peers encounter, e.g. on more personalized media platforms, such as social networks.

Our findings raise also questions regarding the relationship between the common core and diverse exposure. In the traditional mass media, those two concepts would typically coincide: the news media would define a common core of topics that the informed public should receive, and within this common core it was task of the media to ensure that the information that the audience receives is sufficiently diverse. It seems that in the online environment, and with the arrival of more personalized news services, common core and diversity are more clearly two separate, if not even competing concepts. There is a common core of issues that users receive via the different (personalized) channels. However, beyond that users of personalized media are more and more exploring a diversity of issues in the long tail, and potentially at the costs of the common core. As our findings show, the common core is getting smaller. However, it is also worth noticing that even for personalized media there still is a common core.

More research is needed to assess what the implications would be for the quality of the public discourse. In a media environment that is increasingly geared toward "giving users a say" and adapting the media offer to individual needs and preferences (New York Times, 2014) one could argue that this is an almost inevitable development. One could also argue that the shrinking common core challenges traditional agenda setting theory but also the media to incorporate mechanisms of news sharing and personalization of online news. As algorithms get smarter and apps that feature personalized news gain popularity, maintaining a certain common core will require innovative measures to help users discover commonalities (Napoli, 2014). Arguably, agenda setting in the age of smart algorithms and Big Data will involve not only or not so much the selection of issues and their position in media outlets but also the procedures and means of joint engagement of diverse users on diverse issues.

In the context of these new developments in algorithmic news personalization and news selections, our results also raise question about who should be entitled with the task of setting the agenda at the long tail. Could here possibly be a role for users? Or for personalized media? Or with the operators of social networks and search engines - as the providers of the architectures of disaggregated, diverse exposure? If so, how would this task relate to that of the role of the traditional news media as agenda setter for the common core? These are questions that are obviously also important in the context of the ongoing public policy discourse on the regulation of platforms, and the role that considerations of media diversity should play in that context. To answer these question, we need to get a better understanding of how these novel and more user-driven forms of diverse exposure to issues relate to the traditional agenda setting and gatekeeping function of the mass media. To what extent do they compete for the attention of users, or usefully complement each other to form an even richer, livelier and more inclusive public sphere? A better understanding of the actual dynamics of, and actors in agenda setting could pave the way for a more functional and less institutional conceptualization of agenda setting.

\section{Media law and policy}

The insights from this paper are particularly pertinent for European media policy, the competences for which are distributed between the European Union and member 
states. Media law and policy have a long tradition of making sure that the traditional mass media can exercise their privileged position as agenda setter and facilitator of the common core. Constitutionally guaranteed media freedoms and privileges come with an obligation, as the European Court of Human Rights continues to emphasis, that the media have to impart information of public interest and ideas related to matters of public interest, thereby stressing the commitment of the news media to the common core (ECtHR, 1991a, 1991b). Legal constructs such as the so-called list of important events, the right to short reporting but also the must carry and due prominence rules share the objective to preserve the role of (certain) media as "general interest intermediary". In other words, these instruments seek to guarantee that a broad common core of information is available for the broad public, for example, by ensuring that certain events are publicly accessible on free TV (list of important events), and that certain public interest channels are broadly available (must carry, due prominence rules). In addition, diversity requirements must make sure that to the extent that a common core is guaranteed, the information there is also sufficiently diverse (e.g. through internal pluralism safeguards for the public service media or must-carry rules). Insofar, it is probably fair to say that current media law and policy operates with a more "integrated" system of media diversity. To the contrary, personalized media use, even more so in combination with the trend to disaggregated media consumption through search engines, social networks and news aggregators seems to lead away from this ideal of a broad common core, toward more individualistic modes of exploring the long tail, depending on personal interests and preference.

From media and policy point of view, this observation merits a number of follow-up considerations. First, one may wonder how effective the existing diversity safeguards are in the light of the opportunities from personalized media for the user as self-organizing agenda setter? How much are these rules focused on establishing and maintaining the traditional "common core", and how much room do they leave for new conceptualizations of diversity, like unlocking the long tail, and social diversity? And: what is the relevance of these instruments in the light of the growing influence of aggregation platforms such as social media and search engines, and are new initiatives needed to protect media diversity and some form of common core, also online? These are all questions for further research.

Then there is the question of whether, from the media diversity policy point of view, there is a need to be worried about the impact of personalization on the diversity of exposure and a shrinking common core. As mentioned above, a shift away from the common core toward more disintegrated modes of diverse consumption does not necessarily need to be a problem. Insofar, there is for media law and policy makers and scholars first a need to better conceptualize the role that the user plays in the realization of media diversity policies, and if the user as "well-informed all-rounder" or the "expert citizen" are more conductive to that goal. Moreover, seeing that so far no measures exist to determine under which conditions diverse exposure is diverse enough, or even too diverse, more clarity on the applicable benchmarks against which to measure is needed.

In this context, it is relevant to observe, secondly, that recently, policy makers have shown a renewed interest in how to measure potential risks for media plurality and its applications to media markets (OFCOM, 2012; Valcke, 2011a), but that the tools incorporate socio-demographic indicators to assess the availability of media content to users, and not measure exposure diversity (Helberger, 2015). Developing such measures for exposure diversity is even more important in the light of the trend to personalization, and also the role that new intermediary platforms such as search engines and social networks play in that context. Our research, however, also highlights the fact that when developing such measures, it is important to look critically at our current and still prevailing understanding of diversity, and examine how this relates to new, more disaggregated and personalized modes of media consumption. If under the influence of personalized media and 
personalized media platforms such as social networks, that common core is shrinking, this could be considered as a potential risk indicator. Yet, as we have argued here, a shrinking common core does not need to mean that users consume less diverse, only diverse in a different way. One can doubt whether there is a meaningful way to exact what should be the boundaries of the common core?

Thirdly, further research is warranted on the role of intermediary platforms as mediators of more personalized and decentralized forms of diverse exposure. This question relates to the controversy on the impact of intermediaries on, and potential obligations towards diversity and the carefully preserved common core (European Commission, 2013; High Level Expert Group on Media Freedom and Pluralism, 2013; Foster, 2012). In this context, it is interesting to notice that under the draft proposal for a revised Audiovisual Media Services Directive, the European Commission seems to consider the concept of organizational control as a possible trigger for certain kinds of editorial responsibilities. More specifically, the draft directive acknowledges that video sharing platforms do not have editorial control but that they determine the organization of the content, including by automatic means or algorithms. Based on this reasoning, the draft directive imposes additional organizational requirements. Right now, the proposed extension of the scope of societal responsibilities is limited to the protection of minors, and to take action against hate speech[5]. What is more relevant for the given context, however, is an underlying ratio that in the future could become potentially relevant also in the context of diversity policies. This is the idea that not only the control over contents can trigger a certain measure of societal responsibility and further-reaching obligations (in the sense of the traditional definition of editorial control), but also the control over organizational structures to the extent that these structures influence what selections, and in which way the audience consumes media content.

\section{Conclusion}

Our findings highlight the importance, also for media law and policy makers to pay more attention to the way how users actually engage with content on (personalized) media, but also who these users are. Potentially, it could be only certain categories of users (e.g. young and educated) that run the risk of consuming less diverse, or not sharing the critical common pool of information that is still considered so critical for the public sphere? Could there be a need to diversify diversity policies? Another important point of attention should be the extent to which users are actually free in their consumption choices, or to what extent their choice to, for example, explore the long tail is not, or not only, the result of their own choices or those of their peers.

However, it is important to note that the generalizability of the results of this research is limited, as for all empirical research. The research was carried out at a time where news personalization is still in its infancy. As users become more and more used to personalized news services, the mechanisms on how news personalization affects the shared agenda might change. Additionally, the poor model fit indicates that there are other mechanisms at play that shape the shared agenda that we could not grasp in this research. Finally, although the sample is of high quality and representative to the Dutch population, it is rather small which has an impact on the statistical tests.

While currently much attention is reserved for the role of platforms as information gatekeepers in relationship to the news media, maybe their ability to enable or hinder the audience in discovering and distributing news content is part of what really characterizes their influence on the market place of ideas. Little is still known about the receipts of the algorithms that mediate users choices, the motives that go into programming these algorithms and their effects on the way users find, share and engage with media content. While it is true that users do play a more active role in shaping the information agenda so do the personalized platforms that mediate their choices. The agenda setting role of the traditional media and the impact of some of 
intermediary platforms, most notably app stores, search engines and social networks on media diversity are critical issues in this context and one for whose proper assessment policy makers still lack sufficient data.

What are then the implications of individuals' media consumption for media diversity policies? Without a clearer understanding of what it is that we mean when referring to diversity, and how new, more disaggregated and personalized forms of diverse consumption fit in here, it is impossible to answer this question. Insofar, more research is needed on the conceptualization of exposure diversity, and its role in realizing that objectives and values behind media diversity policies in more general. In that context, not only the role of users but also that of (personalized) platforms deserve attention. Users because through their choices they play an active role in realizing exposure diversity, and platforms because they provide the organizational conditions and architecture for users to make diverse choices.

\section{Notes}

1. General interest intermediaries refer to platforms or services, such as newspapers or (public service) broadcasters that provide users with the opportunity to encounter media content in the general interest, even if that includes contents that one has not been searching for in the first place, contrary to, for example, personalized channels that serve content according to personal preferences and attitudes. The argument that Sunstein makes is that these general interest intermediaries have a critical role to play in the democratic discourse as they are enablers of the public sphere and exposure to diverse content (Sunstein, 2009).

2. www.journalism.org/2016/05/26/news-use-across-social-media-platforms-2016/

3. www.digitalnewsreport.org/essays/2016/people-want-personalised-recommendations/

4. This is a standard model used to predict the impact of dependent variables on a binary dependent variable; The $e^{(b)}$ gives an idea of how the likelihood that a respondent has his or her own personal issue at the top or the bottom model of the agenda changes if they fall into a specific category (for example, a higher education); coefficients that are flagged with stars are statistically significant, meaning that there is at least a 95 per cent probability that this is not a chance finding. This implies that coefficients that are not flagged with stars are not statistically significant. While they have been correctly calculated for the sample, there is at least a 5 per cent chance that the results do not apply to the general population.

5. Article 28 a and Recital 28 of a Proposal for a DIRECTIVE OF THE EUROPEAN PARLIAMENT AND OF THE COUNCIL amending Directive 2010/13/EU on the coordination of certain provisions laid down by law, regulation or administrative action in Member States concerning the provision of audiovisual media services in view of changing market realities, COM/2016/0287 final - 2016/0151 (COD).

\section{References}

Anderson, C. (2004), "The long tail. Wired, 12 (10)", October, available at: www.wired.com/wired/ archive/12.10/tail.html

Bobkowski, P.S. (2015), "Sharing the news: effects of informational utility and opinion leadership on online news sharing", Journalism \& Mass Communication Quarterly, Vol. 92 No. 2, pp. 320-345, doi: 10.1177/1077699015573194.

Breeman, J.M., Breeman, V.E. and Helberger, N. (2011), "On the regulator's plate: exposure diversity in a changing media environment: workshop report and highlights of an expert discussion", Journal of Information Policy, Vol. 1, pp. 370-377.

Castells, M. (2007), "communication, power and counter-power in the network society". International Journal of Communication, Vol. 1, pp. 238-266.

Chaffee, S.H. and Metzger, M.J. (2001), "The end of mass communication?", Mass Communication \& Society, Vol. 4 No. 4, pp. 365-379.

Cheng, J., Adamic, L., Dow, P.A., Kleinberg, J.M. and Leskovec, J. (2014), "Can cascades be predicted?", Proceedings of the 23rd international conference on World Wide Web, ACM, New York, NY, pp. 925-936, doi: 10 1145/2566486.2567997. 
Chomsky, N. (1997), "What makes mainstream media mainstream", Z Magazine, Vol. 10 No. 10, pp. 17-23.

Council of Europe (2007), Declaration of the Committee of Ministers on Protecting the Role of the Media in Democracy in the Context of Media Concentration, Council of Europe, Strasbourg.

Curran, J. (1991), "Rethinking the media as a public sphere", in Dahlgren, P. and Sparks, C. (Eds), Communication and Citizenship: Journalism and the Public Sphere, Routledge, London, pp. 27-57.

ECtHR (1991a), Sunday Times v the United Kingdom (appl. no. 13166/87 26 November 1991).

ECtHR (1991b), Observer and Guardian v the United Kingdom (app no 13585/88 judgment of 26 November 1991).

European Commission (2013), Preparing for a Fully Converged Audiovisual World: Growth, Creation and Values, Green Paper, Brussels.

European Commission (2015), Proposal for a DIRECTIVE OF THE EUROPEAN PARLIAMENT AND OF THE COUNCIL amending Directive 2010/13/EU on the coordination of certain provisions laid down by law, regulation or administrative action in Member States concerning the provision of audiovisual media services in view of changing market realities, COM/2016/0287 final - 2016/0151 (COD).

Fenton, N. (2015), "Post-democracy, press, politics and power", The Political Quarterly, Vol. 87 No. 1, pp. 81-85.

Ferree, M.M., Gamson, W.A., Gerhards, J. and Rucht, D. (2002), "Four models of the public sphere in modern democracies", Theory and Society, Vol. 31 No. 3, pp. 289-324.

Foster, R. (2012), News Plurality in a Digital World, Reuters Institute for Journalism, London.

Gilbert, J. (2014), Common Ground: Democracy and Collectivity in an Age of Individualism, Pluto Press, London.

Habermas, J. (1987/1981), Theory of Communicative Action, Volume Two: Lifeworld and System: A Critique of Functionalist Reason, Translated by Thomas A. McCarthy, Beacon Press, Boston, Mass.

Helberger, N. (2008a), "The media literate viewer", in Hugenholtz, P.B. and Van Eijk, N.A.N.M. (Eds), Dommering-Bundle: Opstellen over Informatierecht Aangeboden aan Prof. Mr. E.J. Dommering, Otto Cramwinckel, Amsterdam, pp. 135-148.

Helberger, N. (2012), "Exposure Diversity as a Policy Goal”. Journal of Media Law, Vol. 4, pp. 65-92.

Helberger, N. (2015), "Media pluralism policies from the user perspective”, in Valcke, P., Sudkos, M. and Picard, R. (Eds), Media Pluralism and Diversity: Concepts, Risks and Global Trends, Palgrave Macmillan, London, pp. 325-340.

High Level Expert Group on Media Freedom and Pluralism (2013), A Free and Pluralistic Media to Sustain European Democracy, High Level Expert Group on Media Freedom and Pluralism, Brussels.

Hindman, M. (2008), The Myth of Digital Democracy, Princeton University Press, Princeton, NJ.

Karppinen, K. (2010), "Rethinking media pluralism and communicative abundance", Observatorio Journal, Vol. 11 No. 4, pp. 151-169.

Karppinen, K. (2012), Rethinking Media Pluralism, Fordham University Press, New York, NY.

Keane, J. (2009), The Life and Death of Democracy, Simon and Schuster, New York.

Kwak, H., Lee, C., Park, H. and Moon, S. (2010), April). "What is Twitter, a social network or a news media?", 19th International Conference on World Wide Web, Raleigh, NC.

McCombs, M.E. and Shaw, D.L. (1972), "The agenda-setting function of mass media", Public Opinion Quarterly, Vol. 36 No. 2, pp. 176-187.

Meiklejohn, A. (1948), Free Speech and Its Relation to Self-Government, Harper, New York, NY.

Napoli, P.M. (2011), "Exposure Diversity Reconsidered." Journal of Information Policy, Vol. 1, pp. 246-259.

Napoli, P.M. (2014), "Digital intermediaries and the public interest standard in algorithm governance", Media Policy Project 7 November 2014, available at: http://blogs.Ise.ac.uk/mediapolicyproject/2014/ 
11/07/digital-intermediaries-and-the-public-interest-standard-in-algorithm-governance/ (accessed 20 June 2016).

New York Times (2014), Innovation, New York Times, New York, NY.

OFCOM (2012), Measuring Media Plurality: Ofcom's Advice to the Secretary of State for Culture, Olympics, Media and Sport, OFCOM, London.

Pariser, E. (2011), The Filter Bubble: What the Internet is Hiding From You, Penguin, London.

Prior, M. (2007), Post-broadcast Democracy: How Media Choice Increases Inequality in Political Involvement and Polarizes Elections, Cambridge University Press, Cambridge, MA.

Russell Neuman, W., Guggenheim, L., Mo Jang, S. and Bae, S.Y. (2014), "The dynamics of public attention: agenda-setting theory meets Big Data." Journal of Communication, Vol. 64 No. 2, pp. 193-214, doi: 10.1111/jcom.12088.

Schauer, F. (1982), Free Speech: A Philosophical Enquiry, Cambridge University Press, Cambridge, MA.

Schudson, M. (1998), The Good Citizen: A History of American CIVIC Life, Martin Kessler Books. New York, NY.

Schumpeter, J.A. (1942), Capitalism, Socialism and Democracy, Harper \& Brothers, New York.

Singer, P., Flöck, F., Meinhart, C., Zeitfogel, E. and Strohmaier, M. (2014), "Evolution of reddit: from the front page of the internet to a self-referential community?", Proceedings of the Companion Publication of the 23rd International Conference on World Wide Web Companion, International World Wide Web Conferences Steering Committee, pp. 517-522.

Sunstein, C.R. (2009), Republic. com 2.0, Princeton University Press, Princeton, NJ.

Thorson, K. and Wells, C. (2015), "Curated flows: a framework for mapping media exposure in the digital age", Communication Theory, Vol. 26 No. 3.

Valcke, P. (2011a), "A European risk barometer for media pluralism: why assess damage when you can map risk?", Journal of Information Policy, Vol. 1, pp. 185-216.

Valcke, P. (2011b), "Looking for the user in media pluralism regulation: unraveling the traditional diversity chain and recent trends of user empowerment in European media regulation", Journal of Information Policy, Vol. 1, pp. 287-320.

Weeks, B.E. and Holbert, R.L. (2013), "Predicting dissemination of news content in social media: a focus on reception, friending, and partisanship", Journalism \& Mass Communication Quarterly, Vol. 90 No. 2, pp. 212-232, doi: 10.1177/1077699013482906.

White, D.M. (1950), "The gate keeper: a case study in the selection of news", Journalism and Mass Communication Quarterly, Vol. 27 No. 4, p. 383.

Ytreberg, E. (2002), "Ideal types in public service television: paternalists and bureaucrats, charismatics and avant-gardist", Media, Culture \& Society, Vol. 24 No. 6, pp. 759-774.

Zuckerman, E. (2014), "New media, new civics?”, Policy \& Internet, Vol. 6 No. 2, pp. 151-168.

\section{Further reading}

Barnhust, K.G. (2011), "The new 'media affect' and the crisis of representation for political communication." The International Journal of Press/Politics, Vol. 16 No. 4, 573-593, doi: 1940161211415666.

Helberger, N. (2008b), "From eyeball to creator - toying with audience empowerment in the audiovisual media service directive", Entertainment Law Review, Vol. 6, pp. 128-137.

Irion, K. and Valcke, P. (2015), "Cultural diversity in the digital age: EU competences, policies and regulations for diverse audio-visual and online content", in Psychogiopoulou, E. (Ed.), Cultural Governance and the European Union, Palgrave Macmillan, Houndmills, New York, NY, pp. 75-90.

Williams, B.A. and Delli Carpini, M. (2004), "Monica and Bill all the time and everywhere: the collapse of gatekeeping and agenda setting in the new media environment", American Behavioral Scientist, Vol. 47 No. 9, pp. 1208-1230. 


\section{About the authors}

Judith Moeller is a postdoctoral researcher at the Department of Communication Science at the University of Amsterdam. She is affiliated with the Amsterdam School of Communication Research. Judith Moeller is the corresponding author and can be contacted at: j.moller@uva.nl

Damian Trilling is Assistant Professor of Political Communication and Journalism at the Department of Communication Science at the University of Amsterdam. He is affiliated with the Amsterdam School of Communication Research.

Natali Helberger is Professor of Information Law at the Institute for Information Law (IViR) at the University of Amsterdam.

Kristina Irion is a researcher at the Institute for Information Law (IViR) at the University of Amsterdam.

Claes de Vreese is Professor and Chair of Political Communication at the Department of Communication Science at the University of Amsterdam.

For instructions on how to order reprints of this article, please visit our website: www.emeraldgrouppublishing.com/licensing/reprints.htm Or contact us for further details: permissions@emeraldinsight.com 